\title{
A Pilot Test of Group Based Cognitive Behavioral Therapy to Augment Vocational Services for Persons With Serious Mental Illness: Feasibility and Competitive Work Outcomes
}

Kukla, Marina, PhD; Strasburger, Amy, M., MA; Salyers, Michelle, P., PhD; Rollins, Angela, L., PhD; Lysaker, Paul, H., PhD

\begin{abstract}
Persons with serious mental illness (SMI) struggle with work functioning even with the assistance of vocational services. The current study sought to address this problem by examining a cognitive behavioral therapy to augment vocational services. Fifty-two adults with SMI receiving vocational services participated in a pre-post feasibility trial of the Cognitive Behavior Therapy for Work Success (CBTw) Intervention. CBTw is a 12- week manualized intervention that addresses cognitive and behavioral factors that impact work functioning. Competitive work outcomes were assessed in the 12 weeks preceding baseline and after the intervention. Results demonstrate strong session attendance and a low attrition rate. There were also significant improvements in work outcomes. Specifically, among participants unemployed at baseline, 50.0\% attained work during follow-up. These findings provide preliminary evidence that CBTw may be a feasible intervention to augment vocational services; further controlled research should examine its benefit to work outcomes in people with SMI.
\end{abstract}

Keywords: cognitive behavioral therapy; supported employment; mental illness; work; employment 
Introduction

Vocational dysfunction is highly prevalent among persons with serious mental illness (SMI; Pogoda et al., 2014). Among veterans who use Veterans Health Administration (VHA) services, unemployed Veterans are significantly more likely to have serious mental illness, including major depression, bipolar disorder, post-traumatic stress disorder, and schizophrenia. In addition, people with SMI who are employed are more likely to work part time rather than full time (Burnett-Zeigler et al., 2011) and experience significantly more on-the-job problems, such as poor performance (Nelson et al., 2015) and losses in work productivity (Adler et al., 2011; Schnurr, Lunney, Bovin, \& Marx, 2009).

Unemployment among the SMI population is particularly problematic because it is associated with a higher risk of poverty and a greater reliance on government entitlements and services. Approximately one third of unemployed people with SMI have annual incomes less than $\$ 10,000$ (Luciano \& Meara, 2014). In addition, persons with mental illness report greater financial troubles, more difficulties covering basic necessities such as food and shelter, and more unsecured debt (Elbogen, Johnson, Wagner, Newton, \& Beckham, 2012). Furthermore, the effects of vocational dysfunction in people with SMI include an array of poor recovery outcomes, such as worsening mental health symptoms and more days of psychiatric hospitalization over time (Kukla, Bond, \& Xie, 2012). In contrast, across prospective studies, benefits of work in psychiatric populations include improved self-esteem, life satisfaction, and global well-being, a reduction in psychiatric symptoms, and a lower risk of psychiatric hospitalization (Luciano, Bond, \& Drake, 2014; Luciano et al., 2016). 
Because the stakes are particularly high with regard to community employment among this vulnerable group, vocational services, such as the Individualized Placement and Support model of supported employment were especially designed and tailored for the SMI population; these services effectively address many common work barriers, resulting in substantially improved competitive work outcomes (Campbell, Bond, Drake, McHugo, \& Xie, 2010). However, national program evaluation data reveal that two-thirds of persons who receive routine VHA supported employment services do not gain competitive employment (Abraham, Yosef, Resnick, \& Zivin, 2017).

One possible explanation for these persistent issues is that individualized vocational services incompletely address many important cognitive and behavioral factors that impact work success (Kukla, McGuire, \& Salyers, 2016). For instance, several unsolved vocational barriers include low work-related self-efficacy (Zivin et al., 2016), low self-esteem (Corbière, Lanctôt, Sanquirgo, \& Lecomte, 2009), self stigma (Lysaker, Davis, Bryson, \& Bell, 2009a), poor work motivation, loss of hope and belief that work is unattainable (Waynor \& Pratt, 2011), interpersonal problems (Kukla, Bonfils, \& Salyers, 2015), difficulties enacting effective coping skills on the job (Biegel, Stevenson, Beimers, Ronis, \& Boyle, 2009), and psychological stress (Kukla et al., 2015; Kukla, McGuire, et al., 2016). In addition, among persons with SMI, job tenure has been associated with one's perception of competence and efficacy related to the job (Williams, Fossey, Corbière, Paluch, \& Harvey, 2016). In this regard, work may threaten one's existing sense of self, influencing lowered beliefs in one's ability to maintain a job and succeed at work (Williams et al., 2016). 
Cognitive behavioral therapy (CBT) is a potential solution to these barriers that hinder work success among persons with SMI. While CBT interventions were originally targeted to ameliorate symptoms in this population (Wykes, Steel, Everitt, \& Tarrier, 2008), CBT interventions have begun to take a combined approach alongside rehabilitation practices. For instance, a cognitive intervention focused on noncompetitive work experiences has shown beneficial effects on work performance and tenure in persons with chronic schizophrenia receiving support from a protected, time-limited VA work program (Lysaker, Davis, Bryson, \& Bell, 2009b). More recently, interventions combining CBT with various vocational rehabilitation approaches targeting competitive work in the community have emerged. These interventions have been developed for disparate populations, including for example, employed persons on paid leave from work in non-United States settings with varying labor practices and factors influencing work success (Reme, Grasdal, Løvvik, Lie, \& Øverland, 2015); such interventions have utilized time intensive individual CBT modalities that may be difficult to implement in routine US-based service settings. In addition, these few studies have produced inconclusive findings (Boycott, Schneider, \& McMurran, 2016), or failed to detect any improvement in work outcomes associated with receipt of CBT (Schneider et al., 2016). Also of note, most of the existing interventions were tailored to facilitate job acquisition, ignoring other important outcomes, such as job tenure and on-the-job performance, which frequently suffer in the SMI population (Adler et al., 2011; Bond \& Kukla, 2011). Similarly, some research has suggested that perceptions of workplace network support may decline after initial job acquisition, indicating a continued need to address cognitive and behavioral factors that influence interpersonal functioning as workers with SMI remain on the job (Rollins, Bond, Jones, Kukla, \& Collins, 2011). 
To address these shortcomings, we developed a brief group-based CBT intervention termed the "CBT for Work Success" (CBTw) program to augment existing individualized vocational services targeting improvement in a range of competitive work outcomes among persons with SMI. A previous pilot study demonstrated preliminary feasibility of CBTw in routine service settings, evidenced by low dropout rates and strong CBTw session attendance rates. CBTw was also acceptable to both persons with mental illness and to vocational providers. In addition, the receipt of CBTw was associated with higher employment acquisition rates among a small sample of unemployed veterans with SMI (Kukla, Strasburger, \& Lysaker, 2016) compared to typical employment rates of persons who complete vocational services (Abraham et al., 2017). The current study sought to build on this preliminary work and further gauge the feasibility of CBTw intervention by examining attrition and session attendance rates in a larger sample of people with SMI; the study also sought to assess a range of community work outcomes using a pre-post design. Regarding work outcomes, first, it was hypothesized that participants would work significantly more hours and earn more wages after receipt of the 12-week CBTw intervention compared to the 12 weeks prior to the intervention. Second, among persons unemployed at baseline, it was hypothesized that job acquisition rates would be higher than current published rates of employment in VA vocational services alone (Abraham et al., 2017). Lastly, it was hypothesized that compared to baseline, workers would experience increased work effectiveness after receipt of CBTw.

\section{Methods}

\section{Overview}


Veterans with SMI who were receiving supported employment services completed informed consent and then completed the 12-week CBTw intervention. A pre-post trial design was utilized in which competitive employment outcomes were measured at 1) baseline, assessed as the period encompassing the 12 weeks preceding CBTw enrollment, and 2) at the end of the 12-week CBTw intervention period. Because this was a newly developed intervention, a control group design was not used in order to further establish feasibility and begin to understand potential impact on work outcomes in veterans with SMI.

$\underline{\text { Sample }}$

Participants were adults with a diagnosis of a serious mental illness receiving supported employment services at an urban Midwestern VA medical center. Supported employment is an evidence-based vocational model characterized by individualized and person-centered services that take place primarily in the community, rapid job search, job development focused on competitive jobs, and follow-along support (Bond, Drake, \& Becker, 2008). To be eligible for SE services, veterans must have a diagnosis of SMI and an accompanying documented functional impairment. Other study inclusion criteria were presence of a competitive work goal; participants could be currently working in the community or unemployed and searching for work. Exclusion criteria were a major cognitive deficit or severe medical condition that would prevent participation in the intervention and/or competitive community work. All participants with complete follow-up assessments ( $N=52$, excluding $\mathrm{N}=5$ dropouts) and were included in the analyses, regardless of number of sessions attended. At baseline, among the 52 participants who took part in CBTw, 44 were unemployed and 8 were employed in competitive jobs.

\section{Procedure}


Participants were recruited through the supported employment vocational program at the VA Medical Center in three waves in December 2014, April 2015, and August 2015 respectively. Vocational program staff approached eligible participants with an informational sheet about the study. Interested persons were then contacted by the study team and provided further study information. Participants who verbally agreed were then scheduled for an inperson session to provide written informed consent and complete a baseline assessment of background information, work functioning, and severity of psychiatric symptoms. Next, participants took part in weekly CBTw group sessions for 12 weeks. CBTw sessions were facilitated by a licensed clinical psychologist with extensive training in cognitive based approaches and vocational rehabilitation (first author) and well-trained masters level clinicians. Finally, participants completed a post-intervention assessment at the 12 -week follow-up. Participants were paid $\$ 30$ for completion of assessments. All procedures were approved by the [UNIVERSITY] and [VAMC] internal review boards.

\section{Development of the CBTw Intervention}

The CBT for Work Success (CBTw) program was adapted from the Indianapolis Vocational Intervention program (IVIP), a manualized individual and group CBT intervention for persons with schizophrenia engaged in temporary noncompetitive work; research has demonstrated that IVIP leads to better performance and longer tenure of sheltered work (Lysaker et al., 2009b). An empirically based, iterative, step-wise process was utilized to adapt IVIP to fit the needs of persons with a range of mental illnesses who were seeking competitive work in the community (Goldstein, Kemp, Leff, \& Lochman, 2012). First, based on the findings from a nationwide study of supported employment provider perspectives on barriers and 
facilitators to competitive work in veterans with mental illness (Kukla et al., 2015; Kukla, McGuire, et al., 2016) and existing literature (e.g., Corbière et al., 2011), initial revisions to IVIP were made to address the needs of veterans with mental illness seeking competitive work in the community. For instance, modules were added to facilitate job tenure, such as formulating a plan for dealing with and maintaining work successes as they occur. In addition, content was added to increase the emphasis on personal work narrative in order to bolster participants' sense of self with regard to being productive workers in the community. Next, the newly adapted intervention CBTw, was piloted with an initial group of seven participants; exit interviews elicited feedback on the overall usefulness of the CBTw program, the utility of specific content and sessions, and suggestions for improvements. Feedback from participants, group facilitators, and vocational providers then guided further revision of the intervention protocol. Third, the process was repeated with a second group of five participants and a final group of nine participants resulting in a finalized CBTw protocol and participant manual (Kukla, Strasburger, et al., 2016).

\section{$\underline{\text { CBTw Content }}$}

The CBTw program, tailored toward employed and unemployed persons with community work goals, includes 12 sessions that are delivered in a weekly one-hour group format. Sessions focus on identifying and modifying maladaptive thoughts related to work, enhancing self-efficacy and beliefs in one's ability to succeed at work, and increasing beneficial coping and related behavioral strategies that can be applied across competitive employment settings. Session content includes the following modules: Introduction-Work goals and work story; CBT model and work; Thinking about work; Using the 4A's Approach to Enhance Healthy 
Thinking Barriers to work; Coping with stress and anxiety; Coping with anger and difficult emotions; Communication at work; Dealing effectively with people at work; Accepting and Learning from Work Feedback; Managing work success; Personal work success plan.

\section{$\underline{\text { Measures }}$}

Work Outcomes: We measured outcomes at baseline representing 12 weeks preceding the study and 12 weeks later following the conclusion of the CBTw intervention. Following the standard in studies of vocational interventions for persons with mental illness (Bond, Campbell, \& Drake, 2012), competitive work outcomes included employment status (unemployed/employed), total hours worked, and total wages earned in competitive jobs. Work history was measured by the longest time spent in a competitive job in the past as measured in weeks. Among employed participants only, work effectiveness was measured using one item from the Work and Health Interview (Stewart, Ricci, Chee, Morganstein, \& Lipton, 2003). The item, "On days that you worked during the past month, how effective were you in your job," was rated on a scale from $0 \%$ effective to $100 \%$ effective. This measure has been used widely in adult populations with chronic conditions with good criterion-related validity (Stewart et al., 2003).

Clinical functioning: Psychiatric diagnosis was confirmed by electronic medical record chart review. Psychiatric symptoms assessed included depressive symptoms measured by the Beck Depression Inventory-II (BDI-II; Beck, Steer, \& Brown, 1996), anxiety symptoms measured by the Beck Anxiety Inventory-2 (BAl; Beck \& Steer, 1990), and psychotic symptoms measured by the Positive and Negative Syndrome Scale (PANSS; Kay, Fiszbein, \& Opler, 1987). The BDI-II and BAI are 21-item self-report, Likert-scale measures that have been extensively studied, 
demonstrating strong psychometric properties in persons with SMI including the veteran population; the clinician-rated PANSS is comprised of a total score and 5 symptom subscales, including positive, negative, cognitive, hostility, and depression (Bell, Lysaker, Beam-Goulet, Milstein, \& Lindenmayer, 1994). The PANSS has been extensively utilized in persons with SMI with strong reliability and validity.

CBTw Fidelity: Fidelity to the cognitive behavioral model were measured by an independent rater using the an adapted form of the Revised Cognitive Therapy Scale (CTS-R; Milne, Claydon, Blackburn, James, \& Sheikh, 2001) used in our prior CBTw study (Kukla, Strasburger, et al., 2016). The CTS-R is comprised of 7 items rated on a 0 to 6 Likert scale with good to excellent interrater reliability. All CBTw group facilitators maintained good fidelity (fidelity score of 4 or higher on all items) and were provided supervision by the first author to remedy any minor drift from the program model that arose.

\section{Data Analyses}

Data were analyzed using SPSS 22. Descriptive statistics were generated to characterize the nature of the sample and to examine adherence to statistical assumptions. Second, relationships between background characteristics, clinical functioning, and work history with primary work outcomes were investigated using Pearson's correlations and independent groups t-tests. Third, paired samples t-tests examined changes from pre-intervention (12 weeks preceding baseline) to post-intervention (12-week follow-up) on total hours worked and the and total work wages earned. Next, repeated measures analysis of covariance were conducted for the outcomes of hours worked and wages earned controlling for covariates that have been linked with work functioning in the extant literature, including work history and symptom 
severity (Campbell et al., 2010); time receiving vocational services at baseline was also included as a covariate in these models based on previous studies (Abraham et al., 2017) and the premise that participants with a longer receipt of services at baseline may be closer to gaining employment. Lastly, pre-post work performance among those who obtained and maintained work was characterized using descriptive statistics due to small sample size. For tests of significance, $p$ values were set at .05 and Cohen's $d$ was used to characterize effect sizes.

Results

Background Characteristics: As shown in Table 1, the majority of participants were male and evenly split between white and African American ethnicity. The mean age was around 50 years and average income, including disability income, for the total sample was over $\$ 1300$ monthly. The majority of participants had either a mood disorder ( $N=21,40.4 \%)$, including 14 with bipolar disorder and 7 with major depressive disorder, or schizophrenia spectrum disorders ( $N=20,38.5 \%)$ including 10 with schizophrenia and 10 with schizoaffective disorder. The remaining participants had an anxiety disorder $(\mathrm{N}=7,13.5 \%)$ or posttraumatic stress disorder $(\mathrm{N}=4,7.7 \%)$. Participants had a mean receipt of over a year receiving VA vocational services at baseline.

\section{Attrition and Session Attendance}

Participants attended a mean of $7.6(\mathrm{SD}=3.2)$ sessions and the majority $(\mathrm{N}=36,69.2 \%)$ attended 7 or more sessions. Attrition was $8.8 \%$, as 5 participants (out of 57 participants who completed informed consent) dropped out of the study. Of these, four participants dropped out of the study prior to the first session; the fifth participant dropped out after Session 5. Two participants dropped out due to moving out of state and three ceased all services with the VA. 
Further, participants who completed the study did not significantly differ from participants who dropped out regarding background characteristics, diagnosis and clinical functioning at baseline, or work history.

Work History: As demonstrated in Table 1, participants' longest past competitive job had a mean of 79.0 weeks $(S D=72.1)$. Furthermore, participants who gained work at the 12 week follow-up did not differ on duration of longest job held compared with participants who did not obtain work during follow up. In addition, weeks at longest held job was not correlated with total hours worked or total wages earned at the 12-week follow-up.

Clinical Functioning at baseline: As displayed in Table 1, workers and non-workers at baseline did not differ according to psychiatric diagnosis or depressive, anxiety, and psychotic symptom severity. In addition, work outcomes during the 12-week follow-up did not differ as a function of SMI diagnosis; participants with mood disorders, schizophrenia spectrum disorders, and anxiety disorders/PTSD did not significantly differ on hours worked, wages earned, or work effectiveness. Relatedly, symptom levels at baseline did not predict total hours worked nor wages earned in competitive jobs during the follow-up period.

Work Status: At baseline, 8 participants had competitive jobs (15.4\%) whereas 44 participants were unemployed (84.6\%). All 8 participants who were employed at baseline continued to work during the 12 week follow up. Among participants unemployed at baseline $(\mathrm{N}=44), 50.0 \%(\mathrm{~N}=22)$ acquired a competitive job during the 12-week follow-up. Among the full sample, the overall 12-week follow-up employment rate was $57.7 \%$ ( $\mathrm{N}=30$ employed).

Hours worked and wages earned: As shown in Table 2, among the full sample, there was a significant increase in total hours worked in competitive jobs (mean increase of 51.6 hours); 
participants during 12-week study period worked significantly more hours compared with the 12-week period preceding baseline, $t(51)=3.27, p=.00, d=.48$. Participants also earned significantly higher competitive work wages during the follow-up period compared to the 12week period preceding baseline, $\mathrm{t}(49)=2.85, \mathrm{p}=.01, \mathrm{~d}=.42$. Results regarding improvements in primary work outcomes from baseline to follow-up remained significant after controlling for time enrolled in vocational services, work history, and psychiatric symptom severity (available form the first author). Lastly, participants who were engaged in competitive work at baseline $(\mathrm{N}=8)$ experienced an improvement in total hours worked (mean increase of 98.0 hours, $S D=239.92$ ) during the 12-week follow-up.

Work Effectiveness: The 8 participants employed at baseline they reported a $20 \%$ increase in work effectiveness at the follow-up (from $M=46.9 \%$ effectiveness, $S D=47.3$ ) to $M=66.6 \%$ effectiveness, $S D=46.5$ ). Among the full sample who worked in competitive jobs during the intervention period $(\mathrm{N}=30)$, participants reported very high work effectiveness at follow-up (M=88.7\%, SD=13.2).

\section{Discussion}

This pilot examined feasibility and preliminary work outcomes of the CBT for Work Success intervention as an augmentation to VA vocational services. Findings indicate that half of unemployed participants obtained work after participating in the program and all employed persons at baseline continued working, resulting in a total employment rate of nearly $60 \%$. This figure is an improvement compared to typical rates of one-third among persons who obtain work with the help of VA vocational services at the time of discharge from the program (Abraham et al., 2017). 
Further, both unemployed and employed participants at baseline experienced a significant increase in total hours worked and wages earned in competitive jobs. These gains are more compelling given that they remained significant even after accounting for the effects of symptom severity, work history, and time spent receiving vocational services at baseline. Onthe-job benefits also emerged, as workers reported a $20 \%$ increase in work effectiveness after taking part in the intervention; similarly, the full sample reported high mean effectiveness at work near $90 \%$ at follow-up.

These findings build upon the results of the developmental pilot of CBTw, in which it was found that persons with SMI engaged in CBTw, were highly satisfied with it, and perceived that it helped them move toward their work goals in the community (Kukla, Strasburger, et al., 2016; Kukla, Strasburger, Salyers, Rattray, \& Lysaker, 2017). The current results add to this knowledge by further demonstrating the feasibility of the intervention in a larger sample of people with SMI and by examining preliminary work outcomes. Feasibility results of the current study continue to be encouraging, including strong session attendance and relatively low attrition of less than $10 \%$. In addition, these findings tentatively suggest that the intervention may be a beneficial supplement to vocational services. However, though results indicate meaningful pre-post improvements across key work domains, additional controlled research is needed to confirm the full degree of usefulness of the intervention.

Although the current findings were compared to VA vocational program evaluation data, the major limitations of the study is the lack of a control group of VA vocational services alone. This weakness prevents the forming of conclusions regarding the efficacy of CBTw on competitive work outcomes. Accordingly, the next phase in understanding the utility of CBTw 
on work outcomes is to test it in a randomized controlled trial; future steps should also include examination of the mechanisms by which the intervention may impact competitive work outcomes. Other limitations that merit mentioning include the makeup of the sample; all participants were white or African American and the setting was restricted to a populated urban area. Thus, it is unclear to what extent these findings would generalize to other ethnic groups and other geographical areas, such as rural settings. Lastly, the number of participants who were employed at baseline was too small to conduct between-group analyses regarding changes in outcomes. Future work should include larger numbers of employed persons with SMI who may be experiencing common issues of underemployment and underachievement at work.

In conclusion, this study provides preliminary evidence that brief, group-based CBT is a feasible augmentation to individualized vocational services provided in usual service settings. Future randomized controlled research is needed to understand its utility on an array of competitive work outcomes in people with serious mental illness. Early preliminary evidence suggests that the intervention may be helpful for those who are unemployed as well as those who are employed with further work enhancement goals. 


\section{References}

Abraham, K. M., Yosef, M., Resnick, S. G., \& Zivin, K. (2017). Competitive Employment Outcomes Among Veterans in VHA Therapeutic and Supported Employment Services Programs. Psychiatric Services, appi. ps. 201600412.

Adler, D. A., Possemato, K., Mavandadi, S., Lerner, D., Chang, H., Klaus, J., . . . Oslin, D. W. (2011). Psychiatric status and work performance of veterans of Operations Enduring Freedom and Iraqi Freedom. Psychiatric Services, 62(1), 39-46.

Beck, A. T., \& Steer, R. A. (1990). Manual for the Beck anxiety inventory. San Antonio, TX: Psychological Corporation.

Beck, A. T., Steer, R. A., \& Brown, G. K. (1996). Beck depression inventory-II. San Antonio, 78(2), 490-498.

Bell, M. D., Lysaker, P. H., Beam-Goulet, J. L., Milstein, R. M., \& Lindenmayer, J.-P. (1994). Fivecomponent model of schizophrenia: assessing the factorial invariance of the positive and negative syndrome scale. Psychiatry research, 52(3), 295-303.

Biegel, D. E., Stevenson, L. D., Beimers, D., Ronis, R. J., \& Boyle, P. (2009). Predictors of competitive employment among consumers with co-occurring mental and substance use disorders. Research on Social Work Practice.

Bond, G. R., Campbell, K., \& Drake, R. E. (2012). Standardizing measures in four domains of employment outcomes for individual placement and support. Psychiatric Services.

Bond, G. R., Drake, R. E., \& Becker, D. R. (2008). An update on randomized controlled trials of evidence-based supported employment. Psychiatric Rehabilitation Journal, 31(4), 280. 
Bond, G. R., \& Kukla, M. (2011). Is job tenure brief in individual placement and support (IPS) employment programs? Psychiatric Services, 62(8), 950-953.

Boycott, N., Schneider, J., \& McMurran, M. (2016). Evaluation of a cognitive-behavioural intervention augmenting individual placement and support. Mental Health and Social Inclusion, 20(2), 119-125.

Burnett-Zeigler, I., Valenstein, M., Ilgen, M., Blow, A. J., Gorman, L. A., \& Zivin, K. (2011). Civilian employment among recently returning Afghanistan and Iraq National Guard veterans. Mil Med, 176(6), 639-646.

Campbell, K., Bond, G. R., Drake, R. E., McHugo, G. J., \& Xie, H. (2010). Client predictors of employment outcomes in high-fidelity supported employment: a regression analysis. The Journal of nervous and mental disease, 198(8), 556-563.

Corbière, M., Lanctôt, N., Sanquirgo, N., \& Lecomte, T. (2009). Evaluation of self-esteem as a worker for people with severe mental disorders. Journal of Vocational Rehabilitation, $30(2), 87-98$.

Corbière, M., Zaniboni, S., Lecomte, T., Bond, G., Gilles, P.-Y., Lesage, A., \& Goldner, E. (2011). Job acquisition for people with severe mental illness enrolled in supported employment programs: A theoretically grounded empirical study. Journal of Occupational Rehabilitation, 21(3), 342-354.

Elbogen, E. B., Johnson, S. C., Wagner, H. R., Newton, V. M., \& Beckham, J. C. (2012). Financial well-being and postdeployment adjustment among Iraq and Afghanistan war veterans. Military medicine, 177(6), 669-675. 
Goldstein, N. E., Kemp, K. A., Leff, S. S., \& Lochman, J. E. (2012). Guidelines for adapting manualized interventions for new target populations: a step-wise approach using anger management as a model. Clinical Psychology: Science and Practice, 19(4), 385-401.

Kay, S. R., Fiszbein, A., \& Opler, L. A. (1987). The positive and negative syndrome scale (PANSS) for schizophrenia. Schizophr Bull, 13(2), 261-276.

Kukla, M., Bond, G. R., \& Xie, H. (2012). A prospective investigation of work and nonvocational outcomes in adults with severe mental illness. The Journal of nervous and mental disease, 200(3), 214-222.

Kukla, M., Bonfils, K. A., \& Salyers, M. P. (2015). Factors impacting work success in Veterans with mental health disorders: A Veteran-focused mixed methods pilot study. Journal of Vocational Rehabilitation, 43(1), 51-66.

Kukla, M., McGuire, A. B., \& Salyers, M. P. (2016). Barriers and Facilitators Related to Work Success for Veterans in Supported Employment: A Nationwide Provider Survey. Psychiatric Services, 67, 412-417. doi:DOI:10.1176/appi.ps.201500108

Kukla, M., Strasburger, A. M., \& Lysaker, P. H. (2016). A cognitive behavioral therapy intervention targeting competitive work outcomes for persons with mental illness. Psychiatr Serv, 67(6), 697.

Kukla, M., Strasburger, A. M., Salyers, M. P., Rattray, N. A., \& Lysaker, P. H. (2017). Subjective experiences of the benefits and key elements of a cognitive behavioral therapy focused on community work outcomes in persons with mental illness. Journal of Nervous and Mental Disease, 205(1), 66-73. doi:10.1097/NMD.0000000000000601 
Luciano, A., Bond, G. R., \& Drake, R. E. (2014). Does employment alter the course and outcome of schizophrenia and other severe mental illnesses? A systematic review of longitudinal research. Schizophrenia research, 159(2), 312-321.

Luciano, A., \& Meara, E. (2014). Employment Status of People With Mental Illness: National Survey Data From 2009 and 2010. Psychiatric Services.

Luciano, A., Metcalfe, J. D., Bond, G. R., Xie, H., Miller, A. L., Riley, J., . . Drake, R. E. (2016). Hospitalization Risk Before and After Employment Among Adults With Schizophrenia, Bipolar Disorder, or Major Depression. Psychiatric Services, appi. ps. 201500343.

Lysaker, P. H., Davis, L. W., Bryson, G. J., \& Bell, M. D. (2009a). Effects of cognitive behavioral therapy on work outcomes in vocational rehabilitation for participants with schizophrenia spectrum disorders. Schizophrenia research, 107(2), 186-191.

Lysaker, P. H., Davis, L. W., Bryson, G. J., \& Bell, M. D. (2009b). Effects of cognitive behavioral therapy on work outcomes in vocational rehabilitation for participants with schizophrenia spectrum disorders. Schizophr Res, 107(2-3), 186-191. doi:S09209964(08)00482-9 [pii]

10.1016/j.schres.2008.10.018

Milne, D., Claydon, T., Blackburn, I.-M., James, I., \& Sheikh, A. (2001). Rationale for a new measure of competence in therapy. Behavioural and Cognitive Psychotherapy, 29(01), 21-33.

Nelson, C. B., Zivin, K., Walters, H., Ganoczy, D., MacDermid Wadsworth, S., \& Valenstein, M. (2015). Factors associated with civilian employment, work satisfaction, and performance among National Guard members. Psychiatric Services, 66(12), 1318-1325. 
Pogoda, T. K., Stolzmann, K. L., Iverson, K. M., Baker, E., Krengel, M., Lew, H. L., . . Meterko, M. (2014). Associations Between Traumatic Brain Injury, Suspected Psychiatric Conditions, and Unemployment in Operation Enduring Freedom/Operation Iraqi Freedom Veterans. The Journal of head trauma rehabilitation.

Reme, S. E., Grasdal, A. L., Løvvik, C., Lie, S. A., \& Øverland, S. (2015). Work-focused cognitivebehavioural therapy and individual job support to increase work participation in common mental disorders: a randomised controlled multicentre trial. Occupational and environmental medicine, 72(10), 745-752.

Rollins, A. L., Bond, G. R., Jones, A. M., Kukla, M., \& Collins, L. A. (2011). Workplace social networks and their relationship with job outcomes and other employment characteristics for people with severe mental illness. Journal of Vocational Rehabilitation, 35(3), 243-252.

Schneider, J., Akhtar, A., Boycott, N., Guo, B., Latimer, E., Cao, Z., \& McMurran, M. (2016). Individual placement and support versus individual placement and support enhanced with work-focused cognitive behaviour therapy: Feasibility study for a randomised controlled trial. British Journal of Occupational Therapy, 79(5), 257-269.

Schnurr, P. P., Lunney, C. A., Bovin, M. J., \& Marx, B. P. (2009). Posttraumatic stress disorder and quality of life: extension of findings to veterans of the wars in Iraq and Afghanistan. Clinical psychology review, 29(8), 727-735.

Stewart, W. F., Ricci, J. A., Chee, E., Morganstein, D., \& Lipton, R. (2003). Lost productive time and cost due to common pain conditions in the US workforce. JAMA, 290(18), 24432454. 
Waynor, W. R., \& Pratt, C. W. (2011). Barriers to vocational effectiveness in ACT: Staff perspectives. Journal of the American Psychiatric Nurses Association, 17(1), 72-79.

Williams, A. E., Fossey, E., Corbière, M., Paluch, T., \& Harvey, C. (2016). Work participation for people with severe mental illnesses: An integrative review of factors impacting job tenure. Australian Occupational Therapy Journal.

Wykes, T., Steel, C., Everitt, B., \& Tarrier, N. (2008). Cognitive behavior therapy for schizophrenia: effect sizes, clinical models, and methodological rigor. Schizophr Bull, 34(3), 523-537. doi:sbm114 [pii]

$10.1093 / \mathrm{schbul} / \mathrm{sbm} 114$

Zivin, K., Yosef, M., Levine, D. S., Abraham, K. M., Miller, E. M., Henry, J., . . . Harrod, M. (2016). Employment status, employment functioning, and barriers to employment among VA primary care patients. Journal of affective disorders, 193, 194-202. 
Table 1: Background variables, clinical status, and work history at baseline

\begin{tabular}{|c|c|c|c|c|c|c|c|}
\hline \multirow[b]{2}{*}{ Variable } & \multicolumn{2}{|c|}{$\begin{array}{l}\text { Unemployed at } \\
\text { Baseline } \\
\mathrm{N}=44\end{array}$} & \multicolumn{2}{|c|}{$\begin{array}{l}\text { Employed at } \\
\text { Baseline } \\
\mathbf{N}=8\end{array}$} & \multicolumn{2}{|c|}{ Total $N=52$} & \multirow[t]{2}{*}{$\begin{array}{l}\text { Test of } \\
\text { Significance }\end{array}$} \\
\hline & $\mathbf{M}$ & SD & $\mathbf{M}$ & SD & $\mathbf{M}$ & SD & \\
\hline Age at baseline & 51.20 & 9.41 & 48.25 & 16.11 & 50.75 & 10.55 & ns \\
\hline Monthly income & 1251.45 & 1382.79 & 1610.88 & 940.89 & 1306.74 & 1323.74 & ns \\
\hline Months at longest past job & 81.20 & 74.80 & 67.50 & 58.90 & 79.01 & 72.13 & ns \\
\hline $\begin{array}{l}\text { Weeks enrolled in } \\
\text { vocational services at } \\
\text { baseline }\end{array}$ & 55.35 & 39.84 & 62.39 & 37.31 & 56.43 & 39.19 & \\
\hline BDI-II & 16.32 & 11.12 & 22.63 & 8.09 & 17.29 & 10.89 & ns \\
\hline BAI-II & 13.14 & 10.05 & 19.25 & 11.06 & 14.08 & 10.34 & ns \\
\hline PANSS total & 57.73 & 11.33 & 58.88 & 10.82 & 57.90 & 11.15 & ns \\
\hline PANSS positive & 11.05 & 3.95 & 11.25 & 2.87 & 11.08 & 3.78 & ns \\
\hline PANSS negative & 14.05 & 4.34 & 14.88 & 3.94 & 14.17 & 4.26 & ns \\
\hline PANSS cognitive & 12.55 & 2.45 & 13.00 & 1.77 & 12.62 & 2.35 & ns \\
\hline $\begin{array}{l}\text { PANSS emotional } \\
\text { discomfort }\end{array}$ & 11.70 & 3.97 & 11.38 & 3.93 & 11.65 & 3.93 & ns \\
\hline \multirow[t]{2}{*}{ PANSS hostility } & 6.95 & 2.40 & 6.50 & 1.60 & 6.89 & 2.29 & ns \\
\hline & $\mathbf{N}$ & $\%$ & $\mathbf{N}$ & $\%$ & $\mathbf{N}$ & $\%$ & \\
\hline Gender & & & & & & & ns \\
\hline Male & 39 & $88.6 \%$ & 7 & $87.5 \%$ & 46 & $88.05 \%$ & \\
\hline Female & 5 & $11.4 \%$ & 1 & $12.5 \%$ & 6 & $11.95 \%$ & \\
\hline Race & & & & & & & ns \\
\hline White/Caucasian & 26 & $59.1 \%$ & 4 & $50 \%$ & 30 & $54.55 \%$ & \\
\hline Black/African American & 18 & $40.9 \%$ & 4 & $50 \%$ & 22 & $45.45 \%$ & \\
\hline Mental health diagnosis & & & & & & & ns \\
\hline $\begin{array}{l}\text { Schizophrenia spectrum } \\
\text { disorder }\end{array}$ & 17 & $85 \%$ & 3 & $15 \%$ & 20 & $38.46 \%$ & \\
\hline Mood disorder & 17 & $80.95 \%$ & 4 & $19.05 \%$ & 21 & $40.39 \%$ & \\
\hline Anxiety disorder & 6 & $85.71 \%$ & 1 & $14.29 \%$ & 7 & $13.46 \%$ & \\
\hline PTSD & 4 & $100 \%$ & 0 & $0 \%$ & 4 & $7.69 \%$ & \\
\hline $\begin{array}{l}\text { Highest education } \\
\text { obtained }\end{array}$ & & & & & & & ns \\
\hline $\begin{array}{l}\text { High school graduate or } \\
\text { GED }\end{array}$ & 12 & $27.3 \%$ & 1 & $12.5 \%$ & 13 & $25 \%$ & \\
\hline $\begin{array}{l}\text { Some college (no degree), } \\
\text { technical school or } \\
\text { certification }\end{array}$ & 21 & $47.7 \%$ & 5 & $62.5 \%$ & 26 & $50 \%$ & \\
\hline Associates degree & 0 & $0 \%$ & 1 & $12.5 \%$ & 1 & $1.92 \%$ & \\
\hline Bachelors degree & 8 & $18.2 \%$ & 1 & $12.5 \%$ & 9 & $17.31 \%$ & \\
\hline Masters degree and above & 3 & $6.8 \%$ & 0 & $0 \%$ & 3 & $5.77 \%$ & \\
\hline
\end{tabular}




\begin{tabular}{|c|c|c|c|c|c|c|c|}
\hline & $\mathbf{N}$ & $\%$ & $\mathbf{N}$ & $\%$ & $\mathbf{N}$ & $\%$ & \\
\hline Current housing status & & & & & & & $\mathrm{ns}$ \\
\hline $\begin{array}{l}\text { Lives independently - } \\
\text { alone, with spouse or } \\
\text { roommate }\end{array}$ & 23 & $52.3 \%$ & 5 & $62.5 \%$ & 28 & $53.85 \%$ & \\
\hline $\begin{array}{l}\text { Supportive housing (HUD- } \\
\text { VASH, domiciliary) }\end{array}$ & 12 & $27.3 \%$ & 1 & $12.5 \%$ & 13 & $25 \%$ & \\
\hline $\begin{array}{l}\text { Non-independent (relies on } \\
\text { family) }\end{array}$ & 9 & $20.5 \%$ & 2 & $25 \%$ & 11 & $21.15 \%$ & \\
\hline Marital status & & & & & & & ns \\
\hline Married & 5 & $11.4 \%$ & 1 & $12.5 \%$ & 6 & $11.54 \%$ & \\
\hline Single & 39 & $88.6 \%$ & 7 & $87.5 \%$ & 46 & $88.46 \%$ & \\
\hline
\end{tabular}

${ }^{1}$ Tests of significance pertained to between groups analyses (chi square for categorical variables and independent groups t-tests for continuous variables compared participants who were employed $(\mathrm{N}=8)$ and unemployed $(\mathrm{N}=44)$ using between groups comparisons. significance levels set at $\mathrm{p}<.05$ level

Table 2: Work outcomes at baseline and post-intervention, 12-week follow-up, $\mathrm{N}=52$

\begin{tabular}{lcccc}
\hline Work outcome & 12 weeks preceding baseline & $\begin{array}{l}\text { 12-week follow-up } \\
\text { Post intervention }\end{array}$ & df & t value $(p)$ \\
\hline Total hours worked & $52.12(115.97)$ & $113.88(163.24)$ & 51 & $3.27(.00)^{*}$ \\
Total wages earned & $587.34(1552.28)$ & $1198.21(1984.82)$ & 49 & $2.85(.01)^{*}$ \\
\hline Percent employed & $\mathrm{N}=8(15.1 \%)$ & $\mathrm{N}=30(57.7 \%)$ & \\
& & & \\
\hline
\end{tabular}

